\title{
PREPARATION AND CO-CATALYTIC PROPERTIES OF FUNCTIONALIZED LATICES
}

\author{
Fred Twigt, * Pieter Piet and Anton L. German \\ Laboratory of Polymer Chemistry, Eindhoven University of Technology, P.O. Box 513, $5600 \mathrm{MB}$ \\ Eindhoven, The Netherlands
}

(Received 14 January 1991)

\begin{abstract}
Stable cationic latices were prepared by emulsifier-free emulsion polymerization of styrene with 1-methyl-4-vinylpyridinium bromide or 1-methyl-4-vinylpyridinium iodide as comonomers using azobis(isobutyramidine hydrochloride) as initiator. Comonomers were prepared by a new and simple synthetic procedure. Addition of methanol and especially comonomer increased the surface charge density of cleaned latices and enhanced the polymerization rate. In the presence of iodide, the polymerization rate was lowered. The co-catalytic properties of silica-cleaned latices on the oxidative coupling of 2-mercaptoethanol were tested after cobalt(II)phthalocyanine-tetrasodiumsulphonate (CoTSPc) immobilization onto the functionalized latex particles. A significant increase in oxidation rate was found as compared with the polymer-free CoTSPc system.
\end{abstract}

\section{INTRODUCTION}

Clean, monodisperse latices are frequently used as model systems for studying colloidal stability and for calibrating instruments, e.g. ultracentrifuges and light-scattering units. Usually these latices are prepared by emulsion polymerization in which an emulsifier is used for stabilization of the particles. The disadvantages of using an emulsifier are the difficulty of removing any excess of emulsifier and coagulation of the particles on cleaning the latex [1].

To overcome some of the problems in cleaning latices, the emulsifier is sometimes left out, as first done by Matsumoto et al. [2]. Subsequently many accounts have been published on emulsifier-free polymerization systems in which ionic initiators and comonomers are used for stabilization. These latices are stabilized by:

(i) chemically bound and charged initiator groups;

(ii) hydrophilic groups at the particle-water interface arising from copolymerization of ionic comonomers;

(iii) in situ formed polyelectrolyte, adsorbed on the particles or combinations of (i) to (iii)

Both anionic [3-5] and cationic [6] comonomers have been used in the presence of ionic initiators like azobis(isobutyramidine hydrochloride) and potassium persulphate to prepare these functionalized latices. Alcohols as cosolvents have been shown to improve the polydispersity of the latex particles prepared by emulsion polymerizations [3].

In our laboratory the co-catalytic activity of both functionalized cationic latices and organic supports

*To whom all correspondence should be addressed at: DSM Resins bv, P.O. Box 615, 8000 AP Zwolle, The Netherlands. on the oxidative coupling of thiols to disulphides in the presence of cobalt(II)phthalocyanine-tetrasodiumsulphonate (CoTSPc) is investigated (Scheme 1) The oxidation rate is determined from the oxygen consumption rate and is an indication of catalyst activity. Immobilization of CoTSPc on organic supports severely reduced catalytic activity caused by interparticle and intraparticle diffusion limitations [7]. To overcome mass transfer limitations, small and nonporous functionalized cationic latex particles can be used. Because of the extreme susceptibility of the CoTSPc catalytic system to low cationic polymer concentrations, extensive cleaning of the latices is required. Mainly for this reason, emulsifier-free emulsion polymerization is preferred over the conventional process. The co-catalytic effect of cationic polymers on CoTSPc-catalysed thiol oxidations arises from binding the catalyst, substrate enrichment and formation of active CoTSPc aggregates. The linear charge density of the polymer backbone also appeared to be of crucial importance to the catalytic activity of these homogeneous polymers [8]. Control over surface charge density of these functionalized latices was therefore an important goal.

In this paper we report the use of 1-methyl-4vinylpyridinium bromide (qVPBr) and 1-methyl-4vinylpyridinium iodide ( $\mathrm{qVPI}$ ) as comonomers in the emulsifier-free polymerization of styrene (St), applying azobis(isobutyramidine hydrochloride) (AIBA-2HCl) as initiator. Problems in the synthesis of these comonomers $[9,10]$ have been overcome by a new and simple synthetic procedure. Effects of comonomer concentration and methanol addition on particle size, polymerization rate and surface charge density have been investigated. Based on the findings of these experiments, stable monodisperse latex systems with high surface charge density were selected for catalytic measurements after thorough cleaning. The initial reaction rates in the oxidative coupling of 2-mercaptoethanol are reported and discussed. 

$4 \mathrm{RSH}+\mathrm{O}_{2}$
COTSPC
$2 \mathrm{RSSR}+2 \mathrm{H}_{2} \mathrm{O}$

Scheme 1. Oxidative coupling of thiols in the presence of CoTSPc.

\section{EXPERIMENTAL PROCEDURES}

\section{Apparatus}

Two reactor types were used for polymerizations. For conversion measurements, a $500 \mathrm{~cm}^{3}$ thermostated glass reactor was used, equipped with a rubber septum for sampling and a gas inlet and outlet. Most reactions were conducted in a $1000 \mathrm{~cm}^{3}$ thermostated glass vessel. All polymerizations were carried out under $\mathrm{N}_{2}$, using a disc turbine impeller at $300 \mathrm{rpm}$, keeping temperature at $60^{\circ} \pm 1^{\circ}$.

Thiol oxidations were carried out in an all-glass doublewalled Warburg apparatus, equipped with a mechanical glass stirrer and a pH-electrode (Radiometer GK 2401B). The oxygen uptake rate was measured with a Inacom digital mass flow controller.

A Cambridge S-200 scanning electron microscope was used to determine particle size and particle size distributions. Nuclear magnetic resonance spectra were recorded with a Bruker $200 \mathrm{MHz}$ spectrometer at $25^{\circ}$, using $\mathrm{D}_{2} \mathrm{O}$ as solvent. Spectroscopic measurements were performed with a Hewlett-Packard 8451A diode array spectrophotometer. Conductometric titration curves were recorded on a CDM80 conductivity meter, using a PP1042 cell (Radiometer). Centrifugation was done on a Centrikon T-2060 ultracentrifuge. Amicon serum replacement cells were used with 100 or $200 \mathrm{~nm}$ pore size polycarbonate membranes (Nucleopore).

\section{Materials}

Styrene (Merck) was distilled under $\mathrm{N}_{2}$ at $69^{\circ} / 6 \cdot 10^{3} \mathrm{~Pa}$ to remove inhibitor, and stored at $2^{\circ}$. 4-vinylpyridine (Janssen Chimica) was distilled twice at $31^{\circ} / 5 \cdot 10^{2} \mathrm{~Pa}$ and stored in the dark at $-18^{\circ}$. 2-Mercaptoethanol (Janssen Chimica) was distilled at atmospheric pressure and kept in the dark. Deionized water was used for all polymerizations after purging with argon. Bromomethane (Fluka) and iodomethane (Janssen Chimica), methanol p.a., acetone p.a. (Merck), silica (Merck, Kieselgel 60, 63-200 $\mu \mathrm{m}$ ), hydroquinone (Janssen Chimica) and AIBA $\cdot 2 \mathrm{HCl}$ (Polyscience) were used without further purification.

\section{Synthesis and polymerization procedures}

qVPBr was prepared by adding $0.05 \mathrm{~mol} 4$-vinylpyridine, freshly distilled, in $3 \mathrm{hr}$ to a stirred solution of $0.21 \mathrm{~mol}$ bromomethane in $50 \mathrm{~cm}^{3}$ acetone at $0^{\circ}$. By slowly adding 4-vinylpyridine to an excess of bromomethane, the product is formed instantly and the nucleophilic attack of 4vinylpyridine on $\mathrm{q} \mathrm{VPBr}$ resulting in polymer formation is avoided [9]. After a reaction time of $6 \mathrm{hr}$, the crude product was filtered off and washed several times with acetone.

Yield: $87 \% . \delta\left(\mathrm{D}_{2} \mathrm{O}\right): 4.19 \mathrm{ppm}\left(3 \mathrm{H}, \mathrm{s},-\mathrm{CH}_{3}\right), 6.01 \mathrm{ppm}$ $\left(2 \beta-\mathrm{H}, \mathrm{q},-\mathrm{CH}=\mathrm{CH}_{2}\right), 6.83 \mathrm{ppm}\left(1 \alpha-\mathrm{H}, \mathrm{q},-\mathrm{CH}=\mathrm{CH}_{2}\right)$, $7.88 \mathrm{ppm}(2 \mathrm{~m}-\mathrm{H}, \mathrm{d}, \mathrm{ArH}), 8.52 \mathrm{ppm}(2 o-\mathrm{H}, \mathrm{d}, \mathrm{ArH})$.

For the synthesis of qVPI the same procedure was used. Yield: $91 \% . \delta\left(\mathrm{D}_{2} \mathrm{O}\right): 4.21 \mathrm{ppm}\left(3 \mathrm{H}, \mathrm{s},-\mathrm{CH}_{3}\right), 6.10 \mathrm{ppm}$ $\left(2 \beta-\mathrm{H}, \mathrm{q},-\mathrm{CH}=\mathrm{CH}_{2}\right), 6.85 \mathrm{ppm}\left(1 \alpha-\mathrm{H}, \mathrm{q},-\mathrm{CH}=\mathrm{CH}_{2}\right)$, $7.90 \mathrm{ppm}(2 \mathrm{~m}-\mathrm{H}, \mathrm{d}, \mathrm{ArH}), 8.54 \mathrm{ppm}(2 o-\mathrm{H}, \mathrm{d}, \mathrm{ArH})$.

CoTSPc was synthesized by the method described by Weber et al. [11].

All polymerizations were carried out with $0.42 \mathrm{~mol}$ styrene and $0.92 \mathrm{mmol}$ AIBA $\cdot 2 \mathrm{HCl}$. The total volume of water and methanol was $400 \mathrm{~cm}^{3}$, the quoted concentrations of reactants are based upon this total volume. The reactor was heated to $60^{\circ}$, after which water, monomer and methanol were added. The mixture was stirred at $300 \mathrm{rpm}$ for $10 \mathrm{~min}$ with $\mathrm{N}$, passing through the reactor. Solutions of comonomer and salts dissolved in $5 \mathrm{~cm}^{3}$ of water were added and washed in with an additional $20 \mathrm{~cm}^{3}$ water. When the reaction temperature was reached, a solution of the initiator in $5 \mathrm{~cm}^{3}$ of water was added and washed in with $10 \mathrm{~cm}^{3}$ water. After a reaction time of $18-20 \mathrm{hr}$, the product was heated to $90^{\circ}$ for $2 \mathrm{hr}$ to decompose residual initiator. Finally the latex was filtered to remove any coagulum. Samples for polymerization rate measurements were shortstopped with hydroquinone and conversions were determined by weight based on the amount of polystyrene present.

\section{Cleaning procedures}

Most latices described here were cleaned by centrifuging twice for $30 \mathrm{~min}$ at $20,000-30,000 \mathrm{rpm}$, depending on particle size, to reduce both soluble cationic polymer concentration and ionic strength. After each run, the supernatants were replaced by water of low conductance $(<0.6 \mu \mathrm{S} / \mathrm{cm})$ and the latices were redispersed. $50 \mathrm{~cm}^{3}$ samples were placed in serum replacement cells and washed. Samples of the serum were checked for presence of polyelectrolyte with a VIS spectrophotometric method [12]. In the presence of a CoTSPc solution, $\mathrm{N}^{+}$concentrations of $8 \cdot 10^{-7} \mathrm{~mol} / \mathrm{dm}^{3}$ or more result in an absorbance maximum at $630 \mathrm{~nm}$, originating from the dimeric structure of CoTSPc. If no $\mathrm{N}^{+}$ was detectable, the latices were washed with $1000 \mathrm{~cm}^{3}$ $0.001 \mathrm{~N} \mathrm{NaOH}$ solution to replace all counterions by hydroxyl ions. After washing with $1000 \mathrm{~cm}^{3}$ of water to remove excess of base, the latices were conductometrically titrated with $0.001 \mathrm{~N} \mathrm{HCl}$ under argon.

Latices cleaned according to the described combination of ultracentrifugation and serum replacement still contained adsorbed polyelectrolyte. Desorption during catalytic measurements clearly influenced the oxygen consumption rate [7]. Therefore latices used in catalytic measurements were treated with three portions of silica $\left(2 \mathrm{~g} / 100 \mathrm{~cm}^{3}\right.$ latex $)$ after centrifugation. After shaking the latices with silica for 6-8 hr, the silica was filtered off. Centrifugation of these latices was finally employed to remove possible impurities arising from silica treatment after which they were washed with $1000 \mathrm{~cm}^{3} 0.001 \mathrm{~N} \mathrm{NaOH}$ and $1000 \mathrm{~cm}^{3}$ water in turn. Serum was checked by the CoTSPc method [12].

\section{Catalytic measurements}

The catalyst was prepared by adding an aqueous solution of CoTSPc to the reactor containing the appropriate amount of cleaned latex, with a total reaction volume of $100 \mathrm{~cm}^{3}$. During reactions the reactor was maintained at $25.0 \pm 0.5^{\circ}$, while agitating at $2600 \mathrm{rpm}$ at a total pressure of $1 \cdot 10^{5} \mathrm{~Pa}$. The initial $\mathrm{pH}$ was adjusted by addition of concentrated $\mathrm{NaOH}$ solution. The mixture was twice degassed and saturated with oxygen. After 2-mercaptoethanol injection, the initial reaction rates were measured at the maximum oxygen consumption.

\section{RESULTS AND DISCUSSION}

\section{Emulsion polymerization kinetics}

The key difference between the emulsifier-free emulsion process and conventional emulsion polymerizations is the nucleation period of the polymerization. At the start of the emulsifier-free emulsion polymerization, no monomer swollen micelles are present to absorb the radicals formed by dissociation of the water-soluble initiator. For copolymerization of hydrophilic comonomers, a homogeneous nucleation mechanism has been proposed [13, 14]. 


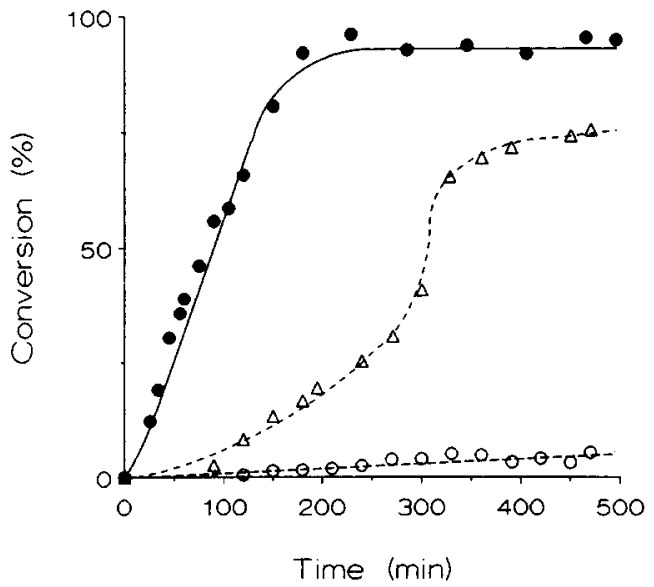

Fig. 1. Conversion-time curves for styrene with various comonomer concentrations. $[\mathrm{qVPBr}]=12.5 \cdot 10^{-3} \mathrm{~mol} / \mathrm{dm}^{3}$ (O), $[\mathrm{qVPBr}]=3.1 \cdot 10^{-3} \mathrm{~mol} / \mathrm{dm}^{3}(\triangle),[\mathrm{qVPBr}]=0 \mathrm{~mol} /$ $\mathrm{dm}^{3}$ (O). [AIBA $\left.\cdot 2 \mathrm{HCl}\right]=2.3 \cdot 10^{-3} \mathrm{~mol} / \mathrm{dm}^{3}, \quad[\mathrm{St}]=$ $1.05 \mathrm{~mol} / \mathrm{dm}^{3},[\mathrm{NaCl}]=8.6 \cdot 10^{-3} \mathrm{~mol} / \mathrm{dm}^{3}$.

The effects of initiator, comonomer and methanol concentrations on polymerization rates and particle size distributions of latices prepared with $\mathrm{qVPBr}$ or qVPI as comonomer show agreement with the homogeneous nucleation mechanism. During the nucleation period, the copolymerization of styrene and these comonomers starts in the aqueous phase. Polymer growth continues until the formed oligomeric radicals reach a critical chain length, determined by the solubility of the growing oligomer in the water phase. Precipitation of these oligoradicals results in primary particles. Increasing the comonomer concentration is thought to increase primary particle stability by enhanced comonomer incorporation [15]. The increase in particle number together with the Trommsdorff gel effect causes the polymerization rate enhancement depicted in Fig. 1. The observed decrease in particle size (Table 1) indicates an increase in particle number over the indicated concentration range of Fig. 1. The adsorption of polyelectrolyte formed at higher comonomer concentrations might also increase primary particle stability.

Increasing initiator and comonomer concentrations initially reduce particle diameter, because of the increase in the number of particles formed during the nucleation period. For both parameters, an increase in particle diameter is observed at high concentrations (Tables 1 and 2). The increase in ionic

Table 1. Effect of comonomer concentration on number-average particle

\begin{tabular}{ccc}
\multicolumn{3}{c}{ diameter } \\
\hline $\begin{array}{c}\text { [qVPBr] } \\
10^{-3} \mathrm{~mol} / \mathrm{dm}^{3}\end{array}$ & $\begin{array}{c}D_{\mathrm{n}} \\
(\mathrm{nm})\end{array}$ & $\bar{D}_{\mathrm{w}} / \bar{D}_{\mathrm{n}}$ \\
\hline 1.2 & 265 & 1.01 \\
3.1 & 175 & 1.01 \\
6.2 & 115 & 1.02 \\
9.4 & 105 & 1.02 \\
12.4 & 130 & 1.02 \\
24.8 & 200 & 1.01 \\
\hline$[\mathrm{AIBA} \cdot 2 \mathrm{HCl}]=2.3 \cdot 10^{-3} \mathrm{~mol} / \mathrm{dm}^{3},[\mathrm{St}]=$ \\
$1.05 \mathrm{~mol} / \mathrm{dm}^{3},[\mathrm{NaCl}]=8.6 \cdot 10^{-3} \mathrm{~mol} /$ \\
$\mathrm{dm}^{3},[\mathrm{methanol}]=2.8 \mathrm{~mol} / \mathrm{dm}^{3}$.
\end{tabular}

Table 2. Effect of initiator concentration on number-average particle diameter

\begin{tabular}{ccc}
\hline $\begin{array}{c}{[\mathrm{AIBA} \cdot 2 \mathrm{HCl}]} \\
10^{-3} \mathrm{~mol} / \mathrm{dm}^{3}\end{array}$ & $\begin{array}{c}\bar{D}_{\mathrm{n}} \\
(\mathrm{nm})\end{array}$ & $\bar{D}_{\mathrm{w}} / D_{\mathrm{n}}$ \\
\hline 0.9 & 145 & 1.01 \\
1.4 & 140 & 1.01 \\
2.3 & 100 & 1.02 \\
4.6 & 140 & 1.01 \\
6.9 & 210 & 1.01 \\
9.2 & 220 & 1.01 \\
\hline$[\mathrm{qVPBr}]=1.2 \cdot 10^{-3} \mathrm{~mol}^{2} / \mathrm{dm}^{3}$, & {$[\mathrm{St}]=$} \\
$1.05 \mathrm{~mol} / \mathrm{dm}^{3},[\mathrm{methanol}]=$ & $2.8 \mathrm{~mol} /$ \\
$\mathrm{dm}^{3}$. &
\end{tabular}

strength which accompanies increasing initiator and comonomer concentrations is believed to dominate the initial concentration effects. Coagulation of primary particles results in enhancement of numberaverage particle diameter [16]. At comonomer concentrations exceeding $25 \cdot 10^{-3} \mathrm{~mol} / \mathrm{dm}^{3}$, bridging was observed by scanning electron microscopy resulting in heterodisperse latices, thus setting a maximum to the use of $\mathrm{qVPBr}$ to control particle properties.

Addition of methanol results in increased styrene incorporation in the water-soluble oligomeric radicals, caused by increased styrene solubility in the continuous phase [17]. Polyelectrolyte formation is therefore partially prevented. The change in solubility of the formed polymers in the presence of methanol results in formation of an increased number of particles. From Fig. 2 and Table 3 it can be seen that the increase in polymerization rate (and decrease in particle diameter) lasts up to a concentration of about $3.1 \mathrm{~mol} / \mathrm{dm}^{3}$. Additional effects of methanol addition were commented upon by Homola et al. [16]. The reported lower polydispersity on methanol addition was also noticed in the present study.

A clear difference was found between the use of qVPBr and qVPI as comonomer. Conversion measurements showed a retardation of polymerization when qVPI was used (Fig. 3). The capability of iodide to retard the polymerization is also indicated

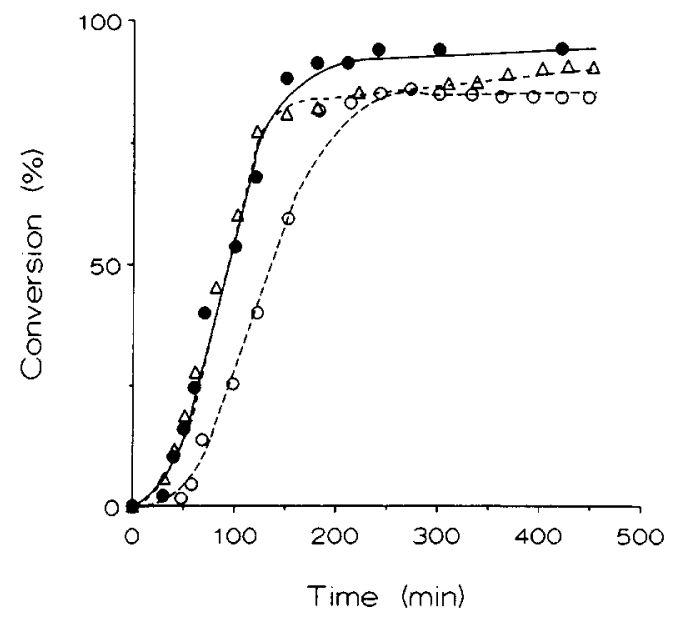

Fig. 2. Conversion-time curves for styrene at various methanol concentrations. [methanol] $=4.9 \mathrm{~mol} / \mathrm{dm}^{3}(\mathrm{O})$, $\left[\right.$ methanol] $=2.8 \mathrm{~mol} / \mathrm{dm}^{3} \quad(\triangle), \quad[$ methanol] $=0 \mathrm{~mol} /$ $\mathrm{dm}^{3}(\mathrm{O})$. [qVPBr] $=1.2 \cdot 10^{-3} \mathrm{~mol} / \mathrm{dm}^{3},[\mathrm{AIBA} \cdot 2 \mathrm{HCl}]=$ $2.3 \cdot 10^{-3} \mathrm{~mol} / \mathrm{dm}^{3}, \quad[\mathrm{St}]=1.05 \mathrm{~mol} / \mathrm{dm}^{3}, \quad[\mathrm{NaCl}]=$ $8.6 \cdot 10^{-3} \mathrm{~mol} / \mathrm{dm}^{3}$. 
Table 3. Effect of methanol concentration on number-average particle

\begin{tabular}{ccc}
\multicolumn{3}{c}{ diameter } \\
\hline $\begin{array}{c}\text { Methano] } \\
\left(\mathrm{mol} / \mathrm{dm}^{3}\right)\end{array}$ & $\begin{array}{c}\bar{D}_{\mathrm{n}} \\
(\mathrm{nm})\end{array}$ & $\bar{D}_{\mathrm{w}} / \bar{D}_{\mathrm{n}}$ \\
\hline 1.2 & 285 & 1.01 \\
2.8 & 265 & 1.01 \\
3.7 & 210 & 1.01 \\
4.9 & 190 & 1.01 \\
\hline$[\mathrm{AIBA} \cdot 2 \mathrm{HCl}]=2.3 \cdot 10^{-3} \mathrm{~mol} / \mathrm{dm}^{3},[\mathrm{St}]=$ \\
$1.05 \mathrm{~mol} / \mathrm{dm}^{3},[\mathrm{qVPBr}]=1.2 \cdot 10^{-3}$ \\
$\mathrm{~mol} / \mathrm{dm}^{3}, \quad[\mathrm{NaCl}]=8.6 \cdot 10^{-3} \mathrm{~mol} /$ \\
$\mathrm{dm}^{3}$.
\end{tabular}

by the experiments shown in Fig. 4. An equimolar amount of sodium iodide clearly lowered the polymerization rate as compared with systems involving sodium chloride and sodium bromide. Preliminary results of experiments seem to indicate that the initiator AIBA-2HCl is capable of reacting with iodide, so forming iodine. The yellowish colour of some latices prepared with qVPI supports iodine formation as is the decolouration on addition of sodium thiosulphate. This iodine formation could explain the retarding effect found in the polymerizations, as iodine is known to be a radical scavenger.

\section{Surface charge density}

The cationic comonomer and initiator residues present at the particle-water interface are responsible for the surface charge of latices prepared by emulsifier-free emulsion polymerization. Surface charge density measurements by determination of the counterion concentration at the particle surface is best accomplished by conductometric titration after replacing the ions with hydroxyl ions. Potentiometric titration of chloride, bromide and iodide ions in cleaned latices with silver nitrate did not give reproducible values. Possibly, replacement of these counterions during latex handling and cleaning by counterions not detectable with silver nitrate must be taken into account. Such problems were not encountered in the conductometric titration with $\mathrm{HCl}$ of the hydroxyl counterions.

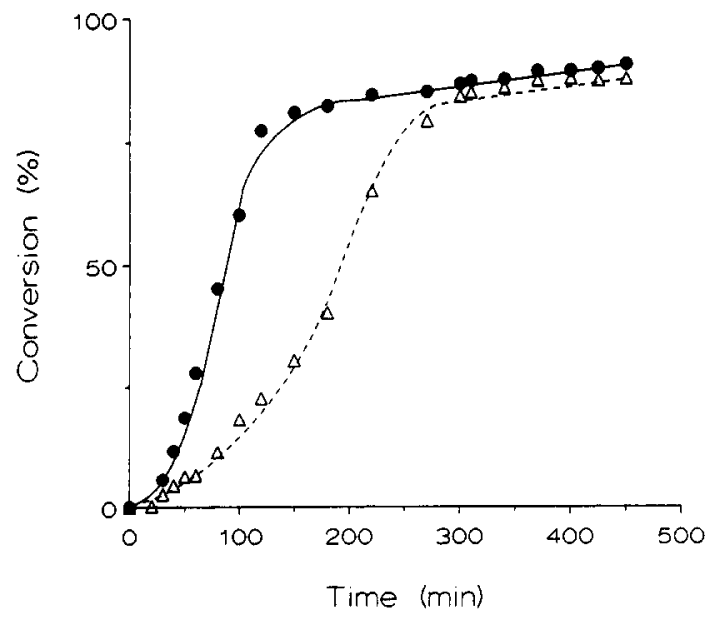

Fig. 3. Effect of comonomer counterion on the conversiontime curves for styrene. $[\mathrm{qVPBr}]=1.2 \cdot 10^{-3} \mathrm{~mol} / \mathrm{dm}^{3}$ (O), $[\mathrm{qVPI}]=1.2 \cdot 10^{-3} \mathrm{~mol} / \mathrm{dm}^{3}(\triangle)$. [AIBA $\left.\cdot 2 \mathrm{HCl}\right]=$ $2.3 \cdot 10^{-3} \mathrm{~mol} / \mathrm{dm}^{3}, \quad[\mathrm{St}]=1.05 \mathrm{~mol} / \mathrm{dm}^{3}$ $8.6 \cdot 10^{-3} \mathrm{~mol} / \mathrm{dm}^{3}$, [methanol] $=2.8 \mathrm{~mol} / \mathrm{dm}^{3}$

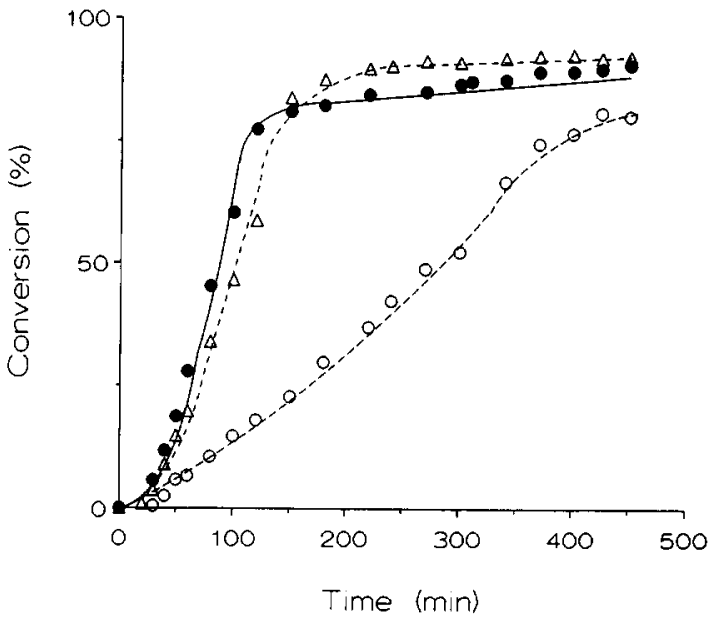

Fig. 4. Effect of halogenide counterion on the conversiontime curves for styrene. $[\mathrm{NaCl}]=8.6 \cdot 10^{-3} \mathrm{~mol} / \mathrm{dm}^{3}(O)$ $[\mathrm{NaBr}]=8.6 \cdot 10^{-3} \mathrm{~mol} / \mathrm{dm}^{3}(\triangle),[\mathrm{NaI}]=8.6 \cdot 10^{-3} \mathrm{~mol} / \mathrm{dm}^{3}$ (O). $[$ AIBA $\cdot 2 \mathrm{HCl}]=2.3 \cdot 10^{-3} \mathrm{~mol} / \mathrm{dm}^{3}, \quad[\mathrm{St}]=1.05 \mathrm{~mol} /$ $\mathrm{dm}^{3}, \quad[q \mathrm{VPBr}]=1.2 \cdot 10^{-3} \mathrm{~mol} / \mathrm{dm}^{3}, \quad$ [methanol] $=2.8 \mathrm{~mol} /$ $\mathrm{dm}^{3}$.

A typical titration curve is given by Fig. 5. Initially the conductivity hardly changes on addition of titrant. When all hydroxyl ions in the electrical double layer are replaced, the conductivity rises rapidly as a result of excess acid added. A more accurate determination of equivalence point is possible by using the back titration technique. Removal of traces of carbon dioxide at low $\mathrm{pH}$ has been indicated to cause this effect [18].

Higher concentrations of comonomer result in an increase in the surface charge density as depicted by Fig. 6. An increasing comonomer content of the copolymer as indicated before is the determining factor. The measured surface charge densities originate both from comonomer and initiator residues. All polymerizations depicted in Fig. 6 reached final conversion in 2-5 hr depending on comonomer concentration. With the $k_{\mathrm{d}}$ [19] for $\mathrm{AIBA} \cdot 2 \mathrm{HCl}$ at $60^{\circ}$

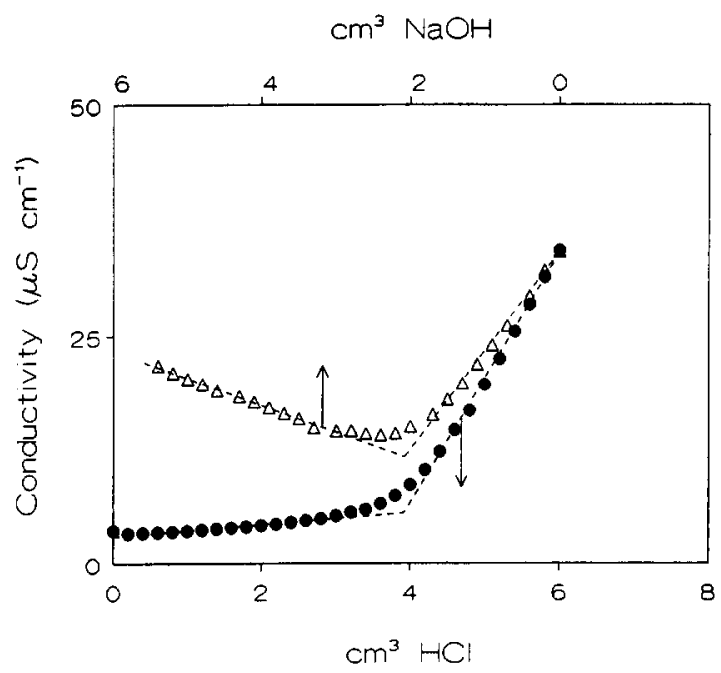

Fig. 5. Typical conductometric titration curves of $20 \mathrm{~g}$ latex $(0.20 \mathrm{~g}$ solid). Titrated with $0.001 \mathrm{~N} \mathrm{HCl}(O)$ followed by back-titration with $0.001 \mathrm{~N} \mathrm{NaOH}(\triangle)$. 


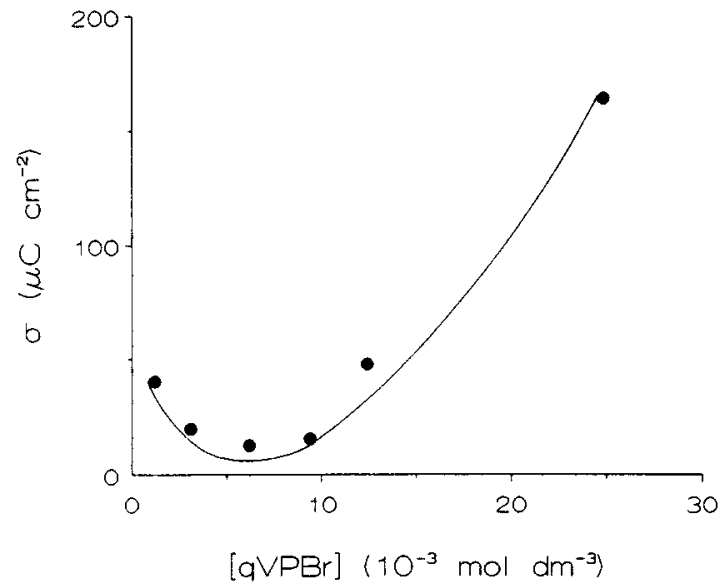

Fig. 6. Effect of comonomer concentration on surface charge density. [AIBA $\cdot 2 \mathrm{HCl}]=2.3 \cdot 10^{-3} \mathrm{~mol} / \mathrm{dm}^{3},[\mathrm{St}]=$ $1.05 \mathrm{~mol} / \mathrm{dm}^{3}, \quad[\mathrm{NaCl}]=8.6 \cdot 10^{-3} \mathrm{~mol} / \mathrm{dm}^{3}, \quad$ [methanol] $=$ $2.8 \mathrm{~mol} / \mathrm{dm}^{3}$.

being $3.2 \cdot 10^{-5} \mathrm{sec}^{-1}$, only $20-60 \%$ of the initiator will have decomposed during the reaction time. Assuming $60 \%$ initiator efficiency, the surface charge densities reported in Fig. 6 would exceed maximum initiator built-in by $10-90 \%$. Therefore, the unaccounted surface charge must result from comonomer units at the particle-water interface. If initiator residues buried in the latex particles and polyelectrolyte formation are considered, even higher comonomer surface coverage must be assumed. Surface charge density control by comonomer addition is limited, however, as mentioned before because of polyelectrolyte formation, resulting in bridging. Although the reported surface charge densities in Fig. 6 are of cleaned latices with serum $\mathrm{N}^{+}$concentrations below $8 \cdot 10^{-7} \mathrm{~mol} / \mathrm{dm}^{3}$, adsorbed polyelectrolyte has to be expected when the values are compared with surface charge densities of silica-treated latices in Table 4. This point clearly indicates the ambiguity of the term 'cleaned latex' frequently encountered in the literature.

Finally, methanol addition results in a constant surface charge density (Fig. 7). Up to a methanol concentration of about $3.1 \mathrm{~mol} / \mathrm{dm}^{3}$, increase in surface charge density is found. In agreement with the effect on particle diameter and polymerization rate (Table 3 and Fig. 2), increase in the number of stable primary particles formed during the nucleation period is most probably responsible for these effects. However, the effect of methanol addition on surface charge density is relatively small as compared with the effect of comonomer.

\section{Catalytic measurements}

The CoTSPc-catalysed oxidative coupling of ME using cationic polymers gives rise to an enzyme-like

Table 4. Characteristics of latices used in catalytic measurements

\begin{tabular}{|c|c|c|c|c|}
\hline Latex & $\begin{array}{c}\text { [qVPBr] } \\
10^{-3} \mathrm{~mol} / \mathrm{dm}^{3}\end{array}$ & $\begin{array}{c}\bar{D}_{\mathrm{n}} \\
(\mathrm{nm})\end{array}$ & $\bar{D}_{\mathrm{w}} / \bar{D}_{\mathrm{n}}$ & $\begin{array}{c}\text { Surface charge density } \\
\left(\mu \mathrm{C} / \mathrm{cm}^{2}\right)\end{array}$ \\
\hline $\begin{array}{l}101 \\
104\end{array}$ & $\begin{array}{l}12.4 \\
18.4\end{array}$ & $\begin{array}{l}265 \\
250\end{array}$ & $\begin{array}{l}1.02 \\
1.02\end{array}$ & $\begin{array}{l}21.4 \\
22.6\end{array}$ \\
\hline
\end{tabular}

$(101)=12.4 \cdot 10^{-3} \mathrm{~mol} / \mathrm{dm}^{3},[\mathrm{NaCl}](104)=6.4 \cdot 10^{-3} \mathrm{~mol} / \mathrm{dm}^{3}$.

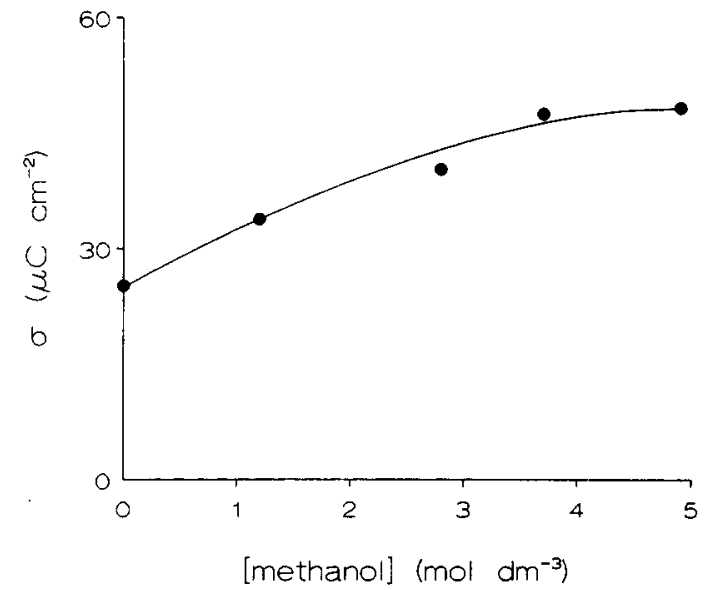

Fig. 7. Effect of methanol addition on surface charge density. [AIBA $\cdot 2 \mathrm{HCl}]=2.3 \cdot 10^{-3} \mathrm{~mol} / \mathrm{dm}^{3},[\mathrm{St}]=1.05 \mathrm{~mol} /$ $\mathrm{dm}^{3},[\mathrm{qVPBr}]=1.2 \cdot 10^{-3} \mathrm{~mol} / \mathrm{dm}^{3},[\mathrm{NaCl}]=8.6 \cdot 10^{-3} \mathrm{~mol} /$ $\mathrm{dm}^{3}$.

kinetic behaviour as indicated earlier in our laboratories. The coupling can be described by a two-substrate Michaelis-Menten model [20] presented in Scheme 2, with $E=C o T S P c, S_{1}=M E, S_{2}=O_{2}$ and $\mathrm{P}=2,2^{\prime}$-dithiodiethanol. An expression for the rate of $\mathrm{ME}$ consumption $(R)$ can be derived assuming pseudo steady-state kinetics in both $\mathrm{ES}_{1}$ and $\mathrm{ES}_{1} \mathrm{~S}_{2}$. At constant oxygen concentration equation (1) results, with $k^{\prime}=4 *\left(k_{3} *\left[\mathrm{O}_{2}\right]\right) /\left(\mathrm{C}_{2}+\left[\mathrm{O}_{2}\right]\right)$ the turnover frequency at $0.1 \mathrm{MPa} \mathrm{O}_{2}$ and saturation in thiol, $K_{\mathrm{M}}^{\prime}=\left(\mathrm{C}_{2} *\left[\mathrm{O}_{2}\right]+\mathrm{C}_{4}\right) /\left(\mathrm{C}_{3}+\left[\mathrm{O}_{2}\right]\right)$ the apparent Michaelis constant, $\mathrm{C}_{2}=\left(\mathrm{k}_{-2}+k_{3}\right) / k_{2}, \mathrm{C}_{3}=k_{3} / k_{\mathrm{l}}$ and $\mathrm{C}_{4}=k_{-1} / k_{1}$.

In Fig. 8 dependence of catalytic activity on pH of latices described in Table 4 is given. Because the reactive species in oxidative coupling of thiols are thiolate anions, increase in rate on increasing $\mathrm{pH}$ is expected $\left[\mathrm{p} K_{\mathrm{a}}(\mathrm{ME})=9.6\right]$. The simultaneous increase in ionic strength, however, is believed to give rise to a competitive ion effect, resulting in the depicted optimum [21, 22]. The dependence of reaction rate on co-catalyst concentration is shown in Fig. 9. For $\mathrm{N}^{+} / \mathrm{Co} \leqslant 4$, no substrate enrichment can occur because of the negative electrostatic charge of the immobilized CoTSPc. For $\mathrm{N}^{+} / \mathrm{Co}>4$, active aggregates of CoTSPc are formed [23]. The optimum here arises from thiolate anion depletion at the active cobalt centre at high co-catalyst concentration. The saturation behaviour typical of enzyme-like kinetics at optimum $\mathrm{pH}$ and $\left[\mathrm{N}^{+}\right]$conditions is depicted in Fig. 10. Both turn-over frequency and apparent Michaelis constant have been calculated from the Lineweaver-Burk plot (Fig. 11) constructed from

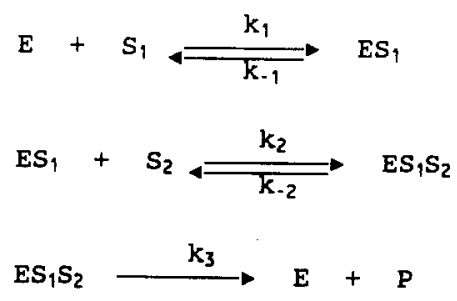

Scheme 2. Two substrate Michaelis-Menten model. 


$$
R=\frac{k^{\prime} *[\text { COTSPC }] *[M E]}{K_{M}^{\prime}+[M E]}
$$

Equation (1). Rate of ME consumption at constant oxygen concentration.

Fig. 10. These constants are indicative of the activity of the immobilized system. In Table 5 these constants are listed together with reported values for the polymer-free system, the homogeneous quaternized poly (4-vinylpyridine) (qPVP) system and the emulsifier-free copolymerized system of styrene and 3-(meth-acrylamidino-propyl) trimethylammoniumchloride(MAD) [24].

Compared with the polymer-free system, the immobilization of CoTSPc on qVPBr latices showed no considerable acceleration of the oxidation rate. Because the absence of mass transport limitations was demonstrated for the latex system, mass transport limitations could not be the cause of the difference in

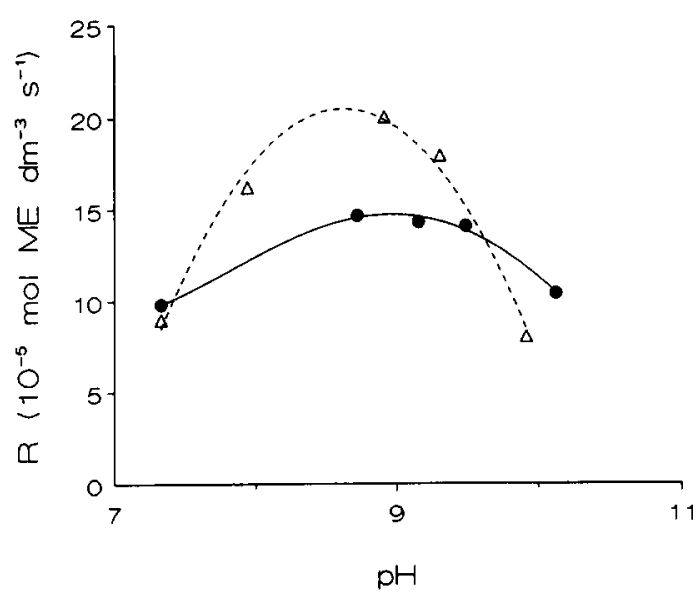

Fig. 8. Catalytic activity as a function of $\mathrm{pH}$ at $25^{\circ}$. $\left[\right.$ CoTSPc] $=2 \cdot 10^{-6} \mathrm{~mol} / \mathrm{dm}^{3},[\mathrm{ME}]=0.143 \mathrm{~mol} / \mathrm{dm}^{3},\left[\mathrm{~N}^{+}\right]$ $(101)=3.3 \cdot 10^{-5} \mathrm{~mol} / \mathrm{dm}^{3}(\dot{O}),\left[\mathrm{N}^{+}\right](104)=5.1 \cdot 10^{-5} \mathrm{~mol} /$ $\mathrm{dm}^{3}(\mathrm{O})$

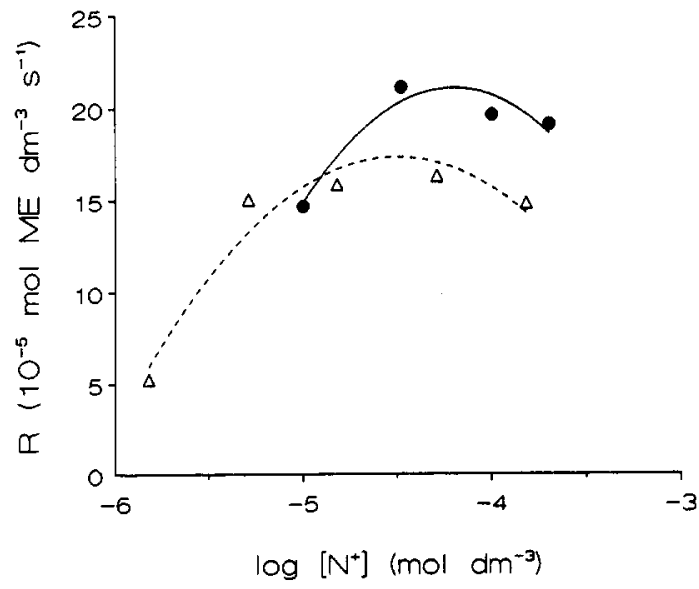

Fig. 9. Catalytic activity as a function of $\left[\mathrm{N}^{+}\right]$at $25^{\circ}$ $[C o T S P c]=2 \cdot 10^{-6} \mathrm{~mol} / \mathrm{dm}^{3},[\mathrm{ME}]=0.143 \mathrm{~mol} / \mathrm{dm}^{3}, \mathrm{pH}=$ 8.8, for latex $101(0)$ and latex $104(0)$. oxidation rates between the homogeneous QPVP system and the qVPBr latex system. Possibly a low linear charge density of the polymer chains is responsible. It has been demonstrated that low linear charge density of polymer chains prevents CoTSPc aggregation necessary for high catalytic activity [8]. Also short hydrophilic blocks of cationic polymer could be present on the particle surface originating from two phenomena. If a high percentage of the $\mathrm{N}^{+}$on the particle surface arises from initiator-capped polystyrene fragments, these charges could be fairly isolated from other cationic groups. This charge isolation would result in CoTSPc isolation instead of aggregation. Also the relatively low $\mathrm{qVPBr} / \mathrm{St}$ ratio, the difference in monomer partition coefficients in combination with unfavourable reactivity ratios of styrene with $\mathrm{qVPBr}$ could contribute to a relatively short hydrophilic block length. Considering the reported dependencies of surface charge density of cleaned latices on methanol, initiator and comon-

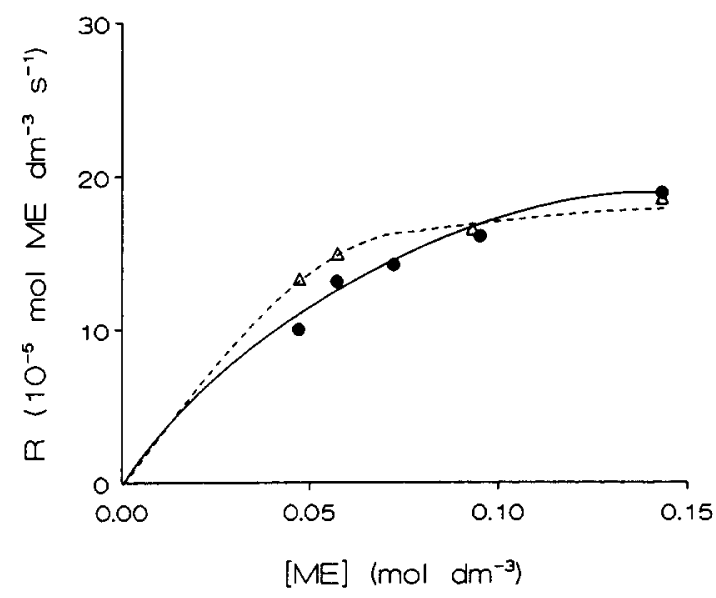

Fig. 10. Catalytic activity as a function of $[\mathrm{ME}]$ at $25^{\circ}$. $[\mathrm{CoTSPc}]=2 \cdot 10^{-6} \mathrm{~mol} / \mathrm{dm}^{3}, \quad \mathrm{pH}=\mathbf{8 . 8}, \quad\left[\mathrm{N}^{+}\right] \quad(101)=$ $6.6 \cdot 10^{-5} \mathrm{~mol} / \mathrm{dm}^{3}(O),\left[\mathrm{N}^{+}\right](104)=5.1 \cdot 10^{-5} \mathrm{~mol} / \mathrm{dm}^{3}(\mathrm{O})$.

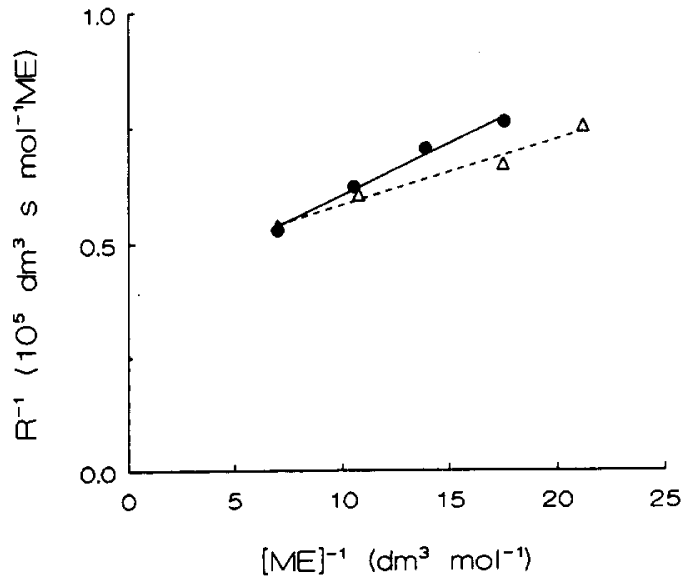

Fig. 11. Lineweaver-Burk plot of immobilized latex systems at $25^{\circ}$. Conditions as Fig. 10. 
Table 5. Turn-over frequencies (mol RSH/mol CoTSPc) and apparent Michaelis constants in oxidative coupling

\begin{tabular}{lcc}
\multicolumn{3}{c}{ of ME } \\
\hline Polymer & $\begin{array}{c}k^{\prime} \\
\left(\mathrm{sec}^{-1}\right)\end{array}$ & $\begin{array}{c}K_{\mathrm{M}} \\
\left(\mathrm{mol} / \mathrm{dm}^{3}\right)\end{array}$ \\
\hline- & 50 & \\
Latex 101 & $169 \pm 31$ & $0.10 \pm 0.01$ \\
Latex 104 & $128 \pm 16$ & $0.05 \pm 0.01$ \\
Latex MAD & $690 \pm 10$ & $0.95 \pm 0.09[7]$ \\
qPVP & $1400 \pm 110$ & $2.6 \pm 0.4[24]$ \\
\hline
\end{tabular}

omer concentrations, variation of these parameters is not expected to affect significantly cationic block length. Comparison of MAD with $\mathrm{qVPBr}$ latices (surface charge density $14.8 \mu \mathrm{C} / \mathrm{cm}^{2}$ and $22.6 \mu \mathrm{C}$ / $\mathrm{cm}^{2}$, respectively) finally indicates that surface charge density is not a dominant factor in the preparation of an active co-catalyst. The distribution of charge along the polymer chains seems more important than the total amount of charge present on the particle surface.

\section{CONCLUSIONS}

Comonomers qVPBr and qVPI can be synthesized easily and are used to prepare stable, monodisperse polystyrene latices under emulsifier-free polymerization conditions. Comonomer concentration, initiator concentration and methanol addition are all versatile tools in controlling particle size and polydispersity of this emulsifier-free polymerization system. The surface charge density can be controlled by comonomer and to a less extent by methanol addition. Although methanol addition results in almost monodisperse latex systems, the surface charge density is only increased slightly. Comonomer addition has a much clearer effect and surface charge densities up to $150 \mu \mathrm{C} / \mathrm{cm}^{3}$ were found. Significant acceleration was found for the CoTSPc-catalysed coupling of 2-mercaptoethanol after immobilization on the qVPBr latices.

Acknowledgements - The authors thank J. Broekman for performing catalytic measurements and the Netherlands Foundation for Emulsion Polymerization (SEP) for financial aid.

\section{REFERENCES}

1. H. J, van den Hul and J. W. Vanderhoff. Br. Polym. J. 2, 121 (1970).

2. T. Matsumoto and A. Ochi. Kobunshi Kagaku 22, 481 (1965).

3. Y. Chonde and I. M. Krieger. J. appl. Polym. Sci. 26, 1819.

4. S. R. Turner, R. A. Weiss and R. D. Lundberg. $J$. Polym. Sci. 23, 535 (1985).

5. H.-S. Chang and S.-A. Chen. J. Polym. Sci. Part A 26, 1207 (1988).

6. L.-J. Liu and I. M. Krieger. J. Polym. Sci.; Polym. Chem. Edn 19, 3013 (1981).

7. K. H. van Streun. Ph.D. thesis, Eindhoven University of Technology, The Netherlands (1990).

8. W. M. Brouwer, P. Piet and A. L. German. J. Molec. Catal. 29, 335 (1985).

9. J. C. Salamone, B. Snider and W. L. Fitch. J. Polym. Sci. Part A-1 9, 1493 (1971).

10. I. Mielke and H. Ringsdorf. J. Polym. Sci.; Polym. Lett. 9, 1 (1971).

11. J. H. Weber and P. H. Bush. Inorg. Chem. 4, 469 (1965).

12. K. H. van Streun, J. Meuldijk and A. L. German. Angew. Makromolek. Chem. 173, 119 (1989).

13. R. M. Fitch, M. B. Prenosil and K. J. Sprick. J. Polym. Sci. Part C 27, 95 (1969)

14. Z. Song and G. W. Poehlein. J. Colloid Interface Sci. 128,486 (1989).

15. J-H. Kim. Ph.D. thesis, Lehigh University, Bethlehem (1987).

16. R. Buscall and R. H. Ottewill. Polymer Colloids. Elsevier, New York (1985).

17. A. M. Homola, M. Inoue and A. A. Robertson. J. appl. Polym. Sci. 19, 3077 (1975).

18. J. Blaakmeer and G. J. Fleer. Colloids and Surf. 36, 439 (1989).

19. N. Minamii, B. Yamada and T. Otsu. Mem. Fac. Eng., Osaka City Univ. 28, 101 (1987).

20. C. Tanford. Physical Chemistry of Macromolecules. Wiley, New York (1961).

21. A. M. van Herk, K. H. van Streun, J. van Welzen and A. L. German. Br. Polym. J. 21, 125 (1989).

22. J. H. Schutten, P. Piet and A. L. German. Makromolek. Chem. 180, 2341 (1979).

23. J. van Welzen, A. M. van Herk and A. L. German. Makromolek. Chem. 188, 1923 (1987).

24. K. H. van Streun, R. Tennebroek, P. Piet and A. L. German. Makromolek. Chem. 191, 2181 (1990). 